\title{
Comparative Analysis of Women's Health Living in Villas and those Living in Apartments in Esfahan
}

\author{
Seyedeh Marziah Tabaeian * and Reyhaneh Amini \\ Faculty of Architecture, Islamic Azad University of Esfahan (Khorasgan), Isfahan, Iran. \\ *marziehtabaeian@gmail.com
}

In the old city of Esfahan which has been renowned as a garden city, people are growingly moving towards purchasing apartments instead of villas as the prices of land and properties have risen, whereas the historical background of this city demonstrates that people used to live in houses with spacious courtyards which had trees, greenery, and in big ones a pond with little fish. The aim of this study is to examine if there a difference among the health of people who live in apartments and those who live in villas in Esfahan. In order to achieve this, first, the definitions and concepts of mental and physical health, inner peace are mentioned and then the effects of greenery inside houses on the quality of the house and its residents' feelings and behaviors are analyzed thoroughly. The results indicated that those who live in villas are healthier than those who live in apartments.

Keywords: Mental and physical health, Nature, Villas, Apartments in Isfa

\section{INTRODUCTION}

Residents' satisfaction with their homes and neighborhood has been a popular research topic for a number of years (Taylor, 1984; Tognoli, 1987). Today, urbanization and being far from nature (natural and environmental elements) have caused considerable harms to human beings. The rush to the cities and lack of space caused the loss of natural spaces (even houses' courtyards). This new form of urbanism is called apartment life. This issue is one of the most important causes of stress and pressure on human beings. (Brown, \&Morgue, 2007). There is plenty of evidence that access and exposure to natural, especially green spaces may enhance the well-being of people living in urban environments. The evidence includes epidemiological studies on green space and decreased mortality (Mitchell \& Popham, 2008; Richardson \& Mitchell, 2010; Richardson et al., 2012; Takano, Nakamura, \& Watanabe, 2002) and decreased morbidity (Maas, Verheij, deVries, Spreeuwenberg, Schellevis, \& Groenewegen, 2009). Experimental studies indicated physiological, attentional and emotional stress-recovery in green space (Bowler, Buyung-Ali, Knight, \& Pullin, 2010), intervention studies showed positive effects of garden therapy on depressive patients (Gonzalez, Hartig, Patil, Martinsen, \& Kirkevold, 2011; Kim, Lim, Chung, \& Woo, 2009), and descriptive and experimental studies revealed that favorite nearby places provide stress-alleviating experiences and serve emotion-regulation (Korpela \& Ylén, 2009; Korpela, Ylén, Tyrväinen, \& Silvennoinen, 2010).

It has been considered that the rush of people toward cities has caused the prominence of the apartment life phenomenon. Furthermore, there is no trace of gardens and home greenery. The fact that plants have a significant role in the vibrancy and fervency of the atmosphere and on the mental and physical needs of men, the necessity of creating a qualified space and a residential place to meet the needs and also establish the connection between men and nature has been acutely felt. This study aims to respond to these two basic questions:

1) Can domestic green plants create mental and physical peace in a human being?

2) How is the physical health of those living in apartments compering to those living in villas?

In the Iranian society, women usually spend more time in houses than men, therefore the effect of the houses' skeletal atmosphere on their body and mind gains more and more importance. In this study, because of prominent presence of women in their houses, we have analyzed their mental state in connection with domestic greenery. 


\subsection{Background}

In this body of literature, some researches on restorative places in the fields of environmental psychology, urban planning, and health behavior which focused on common outdoor places and their effects on individual health and well-being are considered. Research on therapeutic landscapes and healthy geography, including recreation and leisure studies, often examined the benefits of specified built and natural places outside the context of everyday living. Another trend in the literature on therapeutic landscapes has been on place-based therapies for healing, often targeting specific health problems like substance abuse (DeVerteuil et al., 2007), palliative care (Donovan and Williams, 2007), and emotional and relational geographies (Conradson, 2007;). Still many other studies have contributed a layer of understanding about the connections between engaging with nature and the potential benefits for both nature and human health. For instance, studies by Carrus et al. (2008), Ewert et al. (2005), and Hartig et al. (2001) suggest that engaging with nature can encourage people to learn and care about the natural world and to adopt pro-environmental behaviors. More specifically at the individual level, studies suggest that being in natural environments can restore cognitive attention (Cimprich and Ronis, 2003; Kaplan, 1995; Kaplan and Kaplan, 1989), reduce stress (Parsons et al., 1998; Pretty et al., 2005), lessen symptoms of attention deficit disorder (Kuo and Taylor, 2004; Wells, 2000), encourage physical activity (Hug et al., 2009), enhance quality of life (Ogunseitan, 2005), and strengthen community cohesion (Moore et al., 2006; Teig et al., 2009).

\subsection{Healthy Building}

Health and comfort are important aspects determining the quality of life of an occupant. A healthy building which is capable of fostering health and comfort of the occupants during its entire life cycle, supports social needs and enhances productivity ( Bluyssen, 2010). Pointed out some characteristics that a healthy building should have: a healthy building should not be too densely populated; its window design and layout should facilitate natural ventilation and penetration of daylight; it should be isolated from noise and air pollution sources; its water supply and waste discharge systems should be properly installed, maintained, and managed; and its environmental conditions should be clean and hygienic.
According to Ellen et al. (2001), the neighborhood context influences health through neighborhood institutions and resources, through stresses caused by the physical and social environments, and through neighborhood networks and norms [Ellen IG, Mijanovich T, Dillman KN.2001]. Van Poll (2003) also argues that urban quality is determined by the physical as well as social and planning aspects, suggesting that the perceived residential quality not only depends on the quality of buildings and open space characteristics, but also includes aspects such as social ties in the neighborhood, safety, and environmental deterioration [Van Poll RA. multi-attribute .2003].

\subsection{Highlights}

- People's health is immensely affected by the place they live and their connection to nature.

- Because of the density in residential contextures, the necessity of establishing a connection with the nature within apartment houses is becoming even more necessary.

- Distance from nature causes social isolation and affects the inhabitants' interactions.

- $\mathrm{T}$ The influence of the home's atmosphere is more considerable in women rather than men as they are more likely to spend longer hours at home.

\section{METHODOLOGY}

Hartley (2005) explained that social scientists have made wide use of case studies in examining contemporary real-life situations and providing the basis for the applications of ideas and extension of methods. In order to do this research below instruments were used. In doing so, a reliable questionnaire was used to gather the necessary data. In order to prepare the final questionnaire, the theoretical and experimental basis related to different aspects of health (physical, mental, environmental and social) and also life satisfaction and life quality were analyzed. Mental health is a state of well-being in which the individual realizes his or her own abilities. They can cope with the normal stresses of life, or work productively and fruitfully, they are able to make a contribution to their community (Keyes, 2004). 
Social well- being is defined as an individual's self-report of the quality of their relationship with other people, the neighborhood, and the community (Larson 1996). The key to decide whether a measure of social well- being is part of an individual's health, or whether the measure reflects internal responses to stimuli-feeling, thoughts and behaviors can reflect satisfaction or lack of satisfaction with the social environment. (Larson, 1996)

\section{DATA ANALYSIS}

As a matter of fact this research was carried out in one the Iran's biggest city, Esfahan which is located in the center of Iran. This city is full of industrial zones that led it to growing population. The participants of this study were housewives (excluding widowed, divorced and single women), with age range of 15-80 years old and also women with children who (of any age) currently living at home. In this paper, a reliable questionnaire was used to gather the necessary data. In order to prepare the final questionnaire, the theoretical and experimental basis related to different aspects of health (physical, mental, environmental and social) and also life satisfaction and life quality were analyzed. In order to do the statistical calculations and provide the mass distribution tables, SPSS Windows version 21 was used. The statistical method used for testing the theories was the analysis of variances for comparing the average of different variances based on living in a villa or an apartment. Then the simulative validity of questionnaire was calculated using Cronbach's Alpha. ANOVA was used to compare the mean of health aspect among those living in Apartments or villas.

\subsection{Setting}

The study took place within a town and county in Isfahan, Iran. Although the cities of Iran are located in harsh climates but their system and formation have been successful to create a harmony and balance between the artificial space, nature and men's necessities. (Shokohi, 1994,). This study was done in Isfahan which geographically is located in the central part of the Iranian plateau. This city has a reputation of vibrancy and greenery and having vast gardens because of the Zayanderoud River. The river runs through the middle of the city and little creeks called Madi have emerged from it. These streams also run across the city. The gardens and the urban greenery along the river and streams are among the features that give identity to the city (Ansari \& Haghighatbin, 2008). Besides the presence of nature in city, different kinds of plants and domestic animal are accessible they live together in harmony and connection of human being. In Iran's ancient houses, the house is not secluded from the nature and the presence of nature in the spatial structure of the house is obligatory (Haeri, 2009).

\subsection{Sample}

The participants of this study were housewives (excluding widowed, divorced and single women), with age range of 15-80 years old and also women with children who (of any age) currently living at home. The statistical group for this study consists of women who live in apartments or villas in different zones of Esfahan. In the past, the houses in these districts were all villas, some of them still are, but with the appearance of urbanization process and the rise in the prices of lands, apartments with much more density have been constructed. About 384 women were randomly selected in order to answer the questionnaire, they were assessed by Cochran. In this study 219 villas and 165 apartments were investigated. The method was based on age groups and the district where they live. The aim of the research was to compare the physical, social and mental health of women who live in apartments without courtyards or greenery and women who live in villas with courtyard, greenery, water, and a view of the sky and the sunlight.

\subsection{Villas and Apartments Houses}

An apartment unit consists of a closed space and an open courtyard, in front of the closed space. The closed part includes a few cubes together and it doesn't create any variety or space extension just in internal space of each house unit. The only way which can provide space extension is along the horizontal axis of the cube. In this type of housing the relation with nature is minimized, and usually gardens have been removed. While the villa houses with a historical background have a strong relation between open and semi-open spaces with closed-space. As well as gardens and green spaces are remained in this type of buildings. 


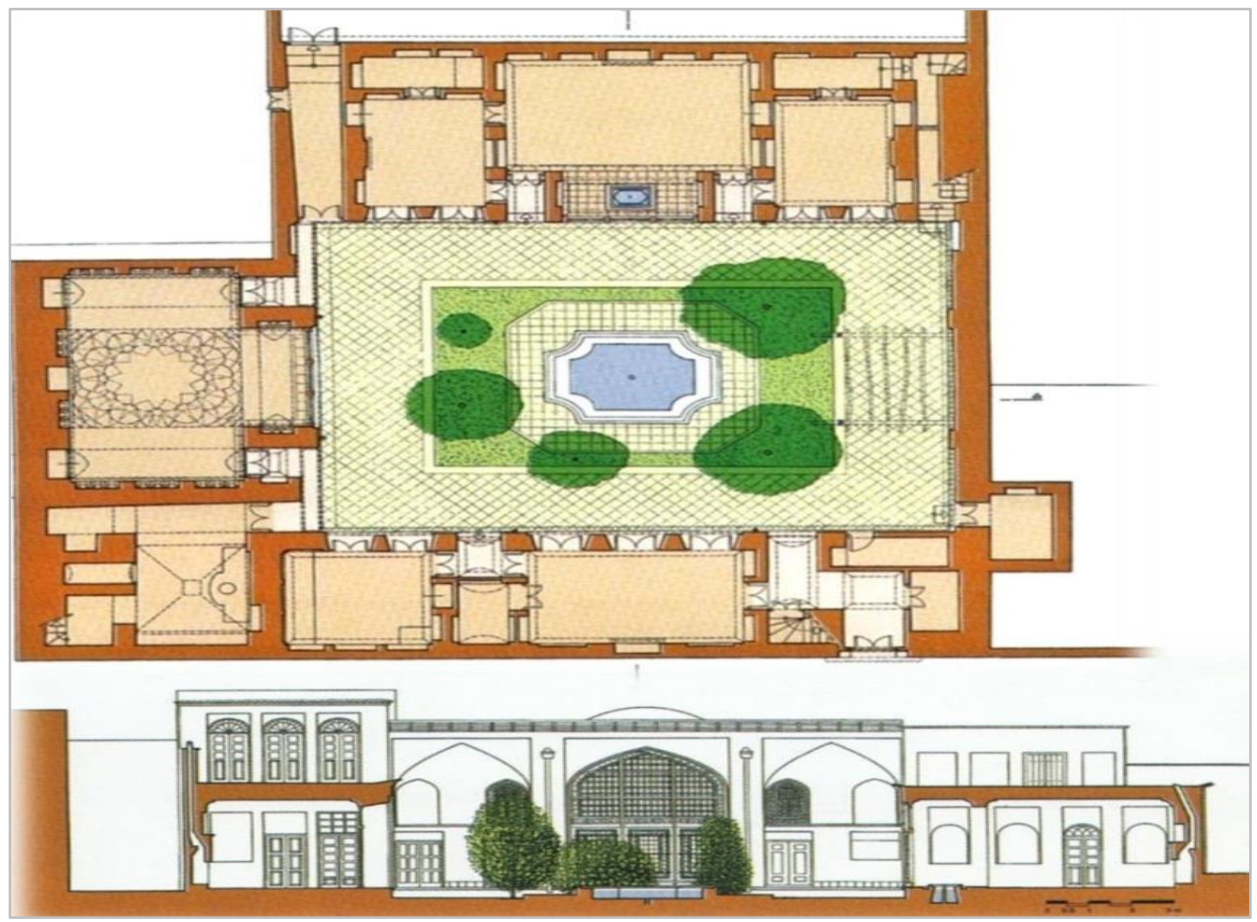

Figure 1: One traditional and historical house of Isfahan and its inner relation with nature

Space structure of contemporary homes has been changed over the years. These changes were rapid and in a massive scale due to the rapid growth of urbanization after 1961 in this country. Space structure of historical houses consists of two main parts, the building and courtyard, although they were forgotten after 1961(Figure. 1). The picture demonstrates the inner part of old house. The garden was in the center of each Iranian house. Pool, flowers, fruit trees and also birds attracted to the garden could be seen in both poor and wealthy houses. In the present circumstances, the possibility of creating such garden is in jeopardy by dense residential development in cities and compressed building plans. In particular, the quality of the house is reduced by the reduction of open space especially in yard, limited vision, and invariable space. The concept of living in apartments has been reduced to biological needs such as sleeping and eating. Space has lost its effective role in this process. And that's why this topic was chosen to study (Figure 2).

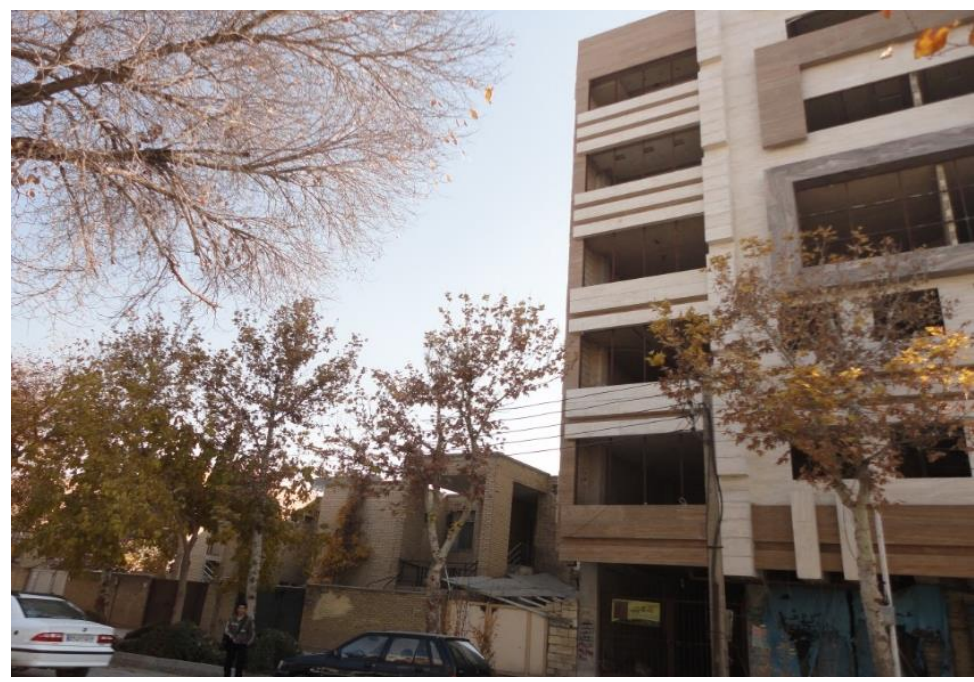

Figure 2: New apartment buildings in Esfahan 


\subsection{The Credibility and Dependability of the Questionnaire}

The indicator of this research (the questionnaire) was obtained from a website which provides researchers with valid questionnaire (www.azmonyar.com). The writers of the study have bought the indicator. In order to evaluate the validity of the questionnaire, the content validity was used. The validity of the content has two types: First the sample validity, and then the simulative validity. To be sure that the questionnaire was valid, different questions were presented after much studying and taking notes and then these questions were gathered. The questionnaire was in relation to the factors that have been studied in this research; physical health, mental health, social health and atmosphere health. The validity of this questionnaire was assured by presenting to researchers and academicians, and by applying their views and comments. Therefore, the questionnaire in general has content validity. To evaluate the dependability of the side dimensions of the questionnaire for measuring the physical, mental, and social and the factors of healthy atmosphere, the internal coordination technique was used and to calculate the dependability factor, the Cronbach Alpha was utilized" Table 1". In continuum, the dependability factors for side dimensions are presented. As it can be seen all the aspects of the questionnaire have an acceptable dependability (more than 0.5). Therefore the results of evaluating the variances are to be trusted to a large extent.

Table 1: Cronbach's Alpha of the Questionnaire

\begin{tabular}{|c|c|c|c|c|}
\hline Variable & $\begin{array}{l}\text { Item } \\
\text { count }\end{array}$ & $\begin{array}{r}\text { Discuss } \\
\text { format } \\
\end{array}$ & $\begin{array}{l}\text { Reliability } \\
\text { coefficient }\end{array}$ & $\begin{array}{c}\text { The } \\
\text { amount of }\end{array}$ \\
\hline Physical health & 8 & $\begin{array}{c}\text { judgmental } \\
\text { sentence }\end{array}$ & cronbach's alpha & $0 / 7$ \\
\hline Mental health & 8 & $\begin{array}{l}\text { judgmental } \\
\text { sentence }\end{array}$ & cronbach's alpha & $0 / 6$ \\
\hline Social health & 8 & $\begin{array}{l}\text { judgmental } \\
\text { sentence }\end{array}$ & cronbach's alpha & $\mathbf{0} / 7$ \\
\hline $\begin{array}{c}\text { Environmental } \\
\text { health }\end{array}$ & 8 & $\begin{array}{c}\text { judgmental } \\
\text { sentence }\end{array}$ & cronbach's alpha & $0 / 6$ \\
\hline
\end{tabular}

\section{RESULTS}

\subsection{Descriptive Results}

The results are presented in two parts of descriptive and inferential results. In the descriptive results section, the most amount of mass was related to the age group of $35-39$ years and the least amount of mass was for the $15-19$ years age group.

\subsection{Inferential Results}

\subsubsection{Hypothesis 1}

The average for different aspects of women's health (physical, mental, atmosphere and social) according to their living in a villa or an apartment is different. In order to test this theory, the $\mathrm{F}$ test, or the one way variance analysis was used because we were looking to find whether the women living in these two types of building have the same level of health or not (villa or apartment). In this test, all the studies were broken into its primary factors and therefore it is also called the variance analysis test. The statistical theories can be presented as

follows:

$$
\begin{aligned}
& H_{\circ}: \mu_{i}=\mu_{j} \\
& H_{1}: \mu_{i} \neq \mu_{j}
\end{aligned}
$$

In null hypothesis, the assumption is that the person's health (in all of its aspects) among the inhabitants of villas and the inhabitants of apartments does not differ and in the opposite theorem (the study), the assumption is that the person's health (in all of its aspects) is different according to the place of living. The average rates of physical, mental, social and atmosphere health of the people who lived in villas were higher than those who lived in apartments. Therefore, generally, the people who live in villas are healthier "Table 2." 
Table 2: Standard Deviation and Mean of various aspects of the health of those living in a villa or an apartment

\begin{tabular}{|c|c|c|c|c|c|}
\hline \multirow{4}{*}{ Apartment } & & $\begin{array}{c}\text { Physical } \\
\text { health }\end{array}$ & $\begin{array}{l}\text { Mental } \\
\text { health }\end{array}$ & Social health & $\begin{array}{c}\text { Environmental } \\
\text { health }\end{array}$ \\
\hline & Mean & $3 / 0675$ & $3 / 3339$ & $3 / 2125$ & $3 / 3160$ \\
\hline & Count & 165 & 165 & 165 & 165 \\
\hline & $\begin{array}{c}\text { Standard } \\
\text { Deviation }\end{array}$ & 0/519733 & $0 / 62747$ & $0 / 35183$ & 0/39492 \\
\hline & Mean & $3 / 2735$ & $3 / 5653$ & $3 / 3764$ & $3 / 7460$ \\
\hline \multirow[t]{3}{*}{ Villa } & Count & 219 & 219 & 219 & 219 \\
\hline & $\begin{array}{c}\text { Standard } \\
\text { Deviation }\end{array}$ & $0 / 49449$ & $0 / 67529$ & 0/39937 & $0 / 39942$ \\
\hline & Mean & $3 / 1850$ & $3 / 4659$ & $3 / 3060$ & $3 / 5612$ \\
\hline \multirow[t]{2}{*}{ Sum } & Count & 384 & 384 & 384 & 384 \\
\hline & $\begin{array}{l}\text { standard } \\
\text { deviation }\end{array}$ & $0 / 51503$ & $0 / 66431$ & $0 / 38780$ & $0 / 45057$ \\
\hline
\end{tabular}

On the other hand, the variance analysis table shows that the inter-group variance is more than the intra-group variance in all aspects of health, and this indicates the fact that the difference in the averages is not caused by chance and in fact the inter-group squares average is an indicative of the independent factor's effect (living in an apartment or a villa) and the intra-group quadrates show the error range, and the big difference indicates that the real difference between various aspects of health among the inhabitants of apartments and villas and the $F$ result, according to the significance level in the table is important for all the aspects of health except the physical health. Therefore, in the case of mental health, health in public relations and healthy atmosphere, the difference in average among the inhabitants of apartments and villas was 95\%. Thus, null hypothesis, which states the lack of difference in mental, social and atmosphere among the inhabitants of apartments and the inhabitants of villas, is rejected. Thus the results presented that there is a big difference in these areas.

But in the case of physical health, as the significance level was more than 0.05 , the hypothesis was rejected and null hypothesis was accepted. In other words, there is no significant difference in the physical health of the inhabitants of apartments and the physical health of the inhabitants of villas. According to the mentioned resulted quadrate eta, it can be expected that $17 \%$ of the mental health variance was related to living in an apartment or a villa, $4 \%$ of the variance of health in social relations related to the place of living and $22 \%$ of the health of the atmosphere variance was determined by the place of living.

Table 3: Eta indicator level to anticipate different aspect of health in villa or apartmen

\begin{tabular}{rcc}
\hline Variables & Eta & Eta squared \\
\hline Physical health & $0 / 198$ & $\mathbf{0 / 0 3 9}$ \\
Mental health & $0 / 030$ & $\mathbf{0 / 1 7 3}$ \\
Social health & $0 / 209$ & $\mathbf{0 / 0 4 4}$ \\
\hline Environmental health & $\mathbf{0 / 4 7 3}$ & $\mathbf{0 / 2 2 4}$ \\
\hline
\end{tabular}




\subsubsection{Hypothesis 2}

The quality of people's lives is different according to their place of living, apartments or villas. In order to test this theory, the F test or the one way variance analysis was used. The statistical theories are presented as follows:
In zero hypothesis, the assumption is that the average life quality among the inhabitants of villas and apartments is not different and the opposite theory assumes that the average life qualities of people are different according to their place of living.

$$
\begin{aligned}
& H_{\circ}: \mu_{1}=\mu_{2} \\
& H_{1}: \mu_{1} \neq \mu_{2}
\end{aligned}
$$

Table 4: Describe standard deviation and mean of quality of life of those living in villa or apartment

\begin{tabular}{ccc}
\hline & Mean & $3 / 3339$ \\
\hline Apartment & Count & 165 \\
& standard deviation & $\mathbf{0 / 6 2 7 4 7}$ \\
& Mean & $3 / 5653$ \\
Villa & Count & $\mathbf{2 1 9}$ \\
& standard deviation & $\mathbf{0 / 6 7 5 2 9}$ \\
& Mean & $3 / 4659$ \\
\hline Sum & Count & $\mathbf{3 8 4}$ \\
\hline & Standard deviation & $\mathbf{0 / 6 6 4 3 1}$ \\
\hline
\end{tabular}

The descriptive "Table 4" indicates that the average life quality of the people who live in villas is higher than the average life quality of those who live in apartments. The table of variance analysis shows that the variance between groups is more than the inner group variance and this shows that the difference among the averages is not caused accidentally and is an indication of the effect of living in villas or apartments. $F$ is significant (the significant level is less than 0.05). Therefore this difference in average of life quality among the inhabitants of apartments and the inhabitants of villas can be stated with a certainty of $95 \%$. Therefore, zero hypothesis is rejected and the theory of the article is accepted. Hence, the average living quality of people who live in villas and people who live in apartments is different and regarding the data given in the average table, the life quality of villa inhabitant is higher than the life quality of the apartment inhabitants.

Table 5: ANOVA for comparison the mean of quality of life in the study population living in Apartments or villas.

\begin{tabular}{cccccc}
\hline $\begin{array}{c}\text { Source of } \\
\text { variance }\end{array}$ & $\begin{array}{l}\text { The sum of } \\
\text { Squares }\end{array}$ & $\begin{array}{c}\text { Degrees of } \\
\text { liberty }\end{array}$ & $\begin{array}{c}\text { Mean } \\
\text { squares }\end{array}$ & $\begin{array}{c}\text { F } \\
\text { statistics }\end{array}$ & $\begin{array}{c}\text { Significance } \\
\text { level }\end{array}$ \\
\hline $\begin{array}{c}\text { Intergroup } \\
\text { Intragroup }\end{array}$ & $5 / 040$ & 1 & $15 / 040$ & $11 / 74$ & $0 / 001$ \\
\hline Sum & $163 / 979$ & 382 & $0 / 429$ & & \\
\hline
\end{tabular}




\subsubsection{Hypothesis 3}

There is a difference in the people's satisfaction of life that lives in apartments or villas. In order to test the theory, the variance analysis test was used. The statistical theories are mentioned below:

$$
\begin{aligned}
& H_{\circ}: \mu_{1}=\mu_{2} \\
& H_{1}: \mu_{1} \neq \mu_{2}
\end{aligned}
$$

The null hypothesis says that the average life satisfaction among the inhabitants of villas and the inhabitants of apartments has no difference and the opposite theory assumes that the average life satisfaction of people is different according to their places of living in Table 6 .

Table 6: Describe standard deviation and mean of Satisfaction with life of those living in villa or apartment

\begin{tabular}{rcc}
\hline & Mean & $\mathbf{3 / 0 7 5 5}$ \\
\hline Villa & Count & $\mathbf{1 6 5}$ \\
& standard & $\mathbf{0 / 7 0 7 7 3}$ \\
& deviation & \\
& Mean & $\mathbf{3 / 3 5 2 6}$ \\
Apartment & Count & $\mathbf{2 1 9}$ \\
& standard & $\mathbf{0 / 8 0 4 3 0}$ \\
& deviation & $\mathbf{3 / 2 3 3 6}$ \\
& Mean & $\mathbf{0 0 0}$ \\
\hline \multirow{2}{*}{ Sum } & Count & $\mathbf{0 / 7 7 5 6 3}$ \\
\hline
\end{tabular}

The descriptive table shows that the average life satisfaction among the people who live in villas is more than the average life satisfaction of those living in apartments. The variance analysis table indicates that the variance between groups is more than the in group variance and this indicates that the difference among the averages is not caused by chance, but it is due to the effect of living in a villa or an apartment. The obtained $\mathrm{F}$ is meaningful. Therefore this average difference can be regarded for the whole statistical group with a certainty of $95 \%$. Therefore, null hypothesis was rejected "Table 7."

Table 7: ANOVA for comparing the mean of Satisfaction of life of those living in Apartments or villas

\begin{tabular}{cccccc}
\hline $\begin{array}{c}\text { Source of } \\
\text { variance }\end{array}$ & $\begin{array}{c}\text { The sum of } \\
\text { squares }\end{array}$ & $\begin{array}{c}\text { Degrees of } \\
\text { liberty }\end{array}$ & $\begin{array}{c}\text { Mean } \\
\text { squares }\end{array}$ & $\begin{array}{c}\text { F } \\
\text { statistics }\end{array}$ & $\begin{array}{c}\text { Significance } \\
\text { level }\end{array}$ \\
\hline Intergroup & $7 / 91$ & 1 & $7 / 191$ & $12 / 307$ & $\mathbf{0 / 0 0 0 1}$ \\
Intragroup & $222 / 020$ & 382 & $0 / 584$ & & \\
\hline Sum & $\mathbf{2 2 9 / 2 1 0}$ & $\mathbf{3 8 3}$ & & & \\
\hline
\end{tabular}

The hypothesis stated a lack of difference in the life quality of the inhabitants of apartments and the inhabitants of villas. Thus, the life satisfaction among the inhabitants of villas is higher.
Regarding the amount of the quadrate eta, it can be expected that up to $3 \%$ variance of the life satisfaction is determined by the person's place of living "Table $8 . "$

Table 8: Eta indicator level to anticipate different aspect of Satisfaction with life in villa and apartment houses

\begin{tabular}{ccc}
\hline Variables & Eta & Eta squared \\
\hline Satisfaction with life & $0 / 177$ & $\mathbf{0 / 0 3 1}$ \\
\hline
\end{tabular}




\section{CONCLUSION}

The historical background of life in Esfahan is in total harmony with nature, as the tourists named the "garden city". Living in the nature is a memory in the minds of the people living in this city. But today, with the rise in the prices of land and the density in the residential areas, we no more hear close relationship between the places of living and the nature. The apartments are constructed in very small scales and with absolutely no connection to nature. Other parts of Iran also have the same process: the traditional houses and villas are being destroyed and turned to smaller and less quality apartments. So the results of this research can be extended to other areas with the same circumstances. In this study, by analyzing three theories and applying statistical method and the variance analysis for comparing the different average variances based on living in villas or apartments in Esfahan, the results show that the average rates of physical, mental, social and atmosphere health of people who live in villas were higher than those who live in apartments. Therefore the women living in villas are healthier. In the second theory, the quality of life was analyzed in these two groups and the results showed that the average life quality of the inhabitants of villas was higher than the average life quality of the inhabitants of apartments. And in the end, the third theory studied the life satisfaction of the participants based on living in apartments or villas and the results indicated that the average life satisfaction is higher in the inhabitants of. In a nutshell, the results revealed that villa settlers are more satisfied than apartment inhabitants.

\section{ACKNOWLEDGMENTS}

I would like to express my gratitude to all those who have directly or indirectly helped me to complete the present thesis. Several people have kindly supported me during the process of carrying out this thesis.

First and foremost, I would like to express my sincere gratitude to my supervisor, Dr. Marziyeh Tabaeian, who provided me with his intellectual support, insightful comments and encouragement.

Further, I am thankful to my translator, for her kind behavior and attempt, Somaye Tajmir
Riahi. In spite of her packed schedule she tried a lot to make the article ready as soon as possible.

Last but not least, I would like to express my sincere gratitude to my dearest family who supported me all through my life. My kind parents and dear husband who are the most important people in my life.

\section{REFERENCES}

Ansari, M. Haghightbin, M. (2008). Garden city, Safavi Utopia, Proceedings of the First Conference of Islamic utopia. Isfahan University.www.azmonyar.com, retrieved from September 2015.

Bluyssen, M, P. (2010). Towards new methods and ways to create healthy and comfortable buildings. Building and Environment 45. 808-818

Bowler, D. E., Buyung-Ali, L. M., Knight, T. M., \& Pullin, A. S. (2010). A systematic review of evidence for the added benefits to health of exposure to natural environments. BMC Public Health, 10, 456e465.

Brown, T, Morgue, B (2007). Off the couch and the move: Global public health and the medication of nature, social science and medicine 64, 1343-1354.

Carrus, G., Passafaro, P., Bonnes, M., (2008). Emotions, habits, and rational choices in ecological behaviors: the case of recycling and use of public transportation. Journal of Environmental Psychology 28, 51-62. Characteristics on stated housing preferences. Housing and Society, 6, 219.

Clarke, J (1990) Health Illness and medicine in Canada, Toronto: MC cell and Stewart.

Conradson, D., (2007). The experiential economy of stillness: places of retreat in contemporary Britain. In: Williams, A. (Ed.), Therapeutic Landscapes. Ashgate, Burlington, VT, pp. 32-48.

Cimprich, B., Ronis, D., (2003). An environmental intervention to restore attention in women with newly diagnosed breast cancer. Cancer Nursing 26 (4), 284-291.

DeVerteuil, G., Wilton, R., Klassen, S. (2007). Making clean and sober places: the 
inter- section of therapeutic landscapes and substance abuse treatment. In: Williams, A. (Ed.), Therapeutic Landscapes. Ashgate, Burlington, VT, pp. 77- 91.

Donovan, R., Williams, A., (2007). Making home space therapeutic for palliative patients and their caregivers. In: Williams, A. (Ed.), Therapeutic Landscapes. Ashgate, Burlington, VT, pp. 199-220.

Ellen IG, Mijanovich T, Dillman KN. (2001). Neighborhood effects on health: exploring the links and assessing the evidence. Journal of Urban Affairs: 23(3-4):391-408. Environmental Stress. New York: Cambridge University Press.

Ewert, A., Place, G., Sibthorp, J., (2005). Early- life outdoor experiences and an individual's environmental attitudes. Leisure Sciences 27 (3), 225-239.

Gonzalez, M. T., Hartig, T., Patil, G. G., Martinsen, E. W., \& Kirkevold, M. (2011). A prospective study of group cohesiveness in therapeutic horticulture for clinical depression. International Journal of Mental Health Nursing, 20, 119e129.

Groot, J., Steg, L., (2009). Mean or green: which values ca promote stable proenvironmental behavior? Conservation Letters 2, 61-66.

Haeri Mazandarani, M. (2009). Housing, culture, nature, historical and contemporary homes criteria in order to develop a process and criteria for the design of the house. Tehran: Studies and Research Center of Planning and Architecture

Hartig, T., Kaiser, F.G., Bowler, P.A., (2001). Psychological restoration in nature as a positive motivation for ecological behavior. Environment and Behavior 33 (4), 590-607.

Hartley, J. (2005). Essential Guide to Qualitative methods in Organizational Research. Atherbaeum Press Ltd, Gateshead

Ho DCW, Leung HF, Wong SK, Cheung AKC, Lau SSY, Wong WS, et al. (2004). Assessing the health and hygiene performance of apartment buildings. Facilities; 22(3/4):58-69.

Addison- Wesley. Behavior, 16, 369
393.

Hug, S. Hartig, T, Hansmann, R., Seeland, and K. Hornung, R. (2009) .Restorative qualities of indoor and outdoor exercise setting as predictors of exercise frequency. Health\& Place 15,971-980.

Kaplan, R., Kaplan, S. (1989).The Experience of Nature: A Psychological Perspective. Cambridge University Press, Cambridge, NY. Kaplan, S. (1995). The restorative benefits of nature: toward an integrative frame- work. Journal of Environmental Psychology $15,169-182$.

Keyes, C.M. and Shapiro, A (2004) "Social well- being in the us: A descriptive epidemiology" in Orville Brim, Carold. Ryff and Ronald C. Kessles (Eds) How healthy are you? A national study of well-being of Midlife, Chicago: university of Chicago press.

Larson, J .S. (1996) "The world health organization" definition of health: social versus spiritual health social indicators research, 3: 181-192.

Kim,W., Lim, S.-K., Chung, E.-J., \&Woo, J. M. (2009). The effect of cognitive behavior therapybased psychotherapy applied in a forest environment on physiological changes and remission of major depressive disorder. Psychiatry Investigation, 6.

Korpela, K., \& Ylén, M. (2009). Effectiveness of favorite place prescriptions: A field experiment. American Journal of Preventive Medicine, 36, 435e438.

Korpela, K., Ylén, M., Tyrväinen, L., \& Silvennoinen, H. (2010). Favorite green, waterside and urban environments, restorative experiences and perceived health in Finland. Health Promotion International, 25, 200e209.

Kuo, F.E., Taylor, A.F., (2004). The potential natural treatment for attention deficit/ hyperactivity disorder: evidence for a national study. American Journal of Public Health 94 (9), 1580-1586.

Maas, J., Verheij, R. A., deVries, S., Spreeuwenberg, P., Schellevis, F. G., \& Groenewegen, P. P. (2009). 
Morbidity is related to a green living environment. Journal of Epidemiology \& Community Health, (63, 967-973).

Mitchell, R., \& Popham, F. (2008). Effect of exposure to natural environment on health inequalities: An observational population study. The Lancet, 372, 1655 e 1660.

Moore, M., Townsend, M., Oldroyd, J., (2006). Linking human and ecosystem health: the benefits of community involvement in conservation groups. Eco-Health Journal of Consortium 3, 255-261.

Ogunseitan, O., (2005). Topo philia and the quality of life. Environmental Health Perspectives 113 (2), 143-148.

Pretty, J., Peacock, J., Sellens, M., Griffin, M., (2005). The mental and physical health outcomes of green exercise. International Journal of Environmental Health Research 15 (5), 319-337.

Richardson, E. A., \& Mitchell, R. (2010). Gender differences in relationships between urban green space and health in the United Kingdom. Social Science \& Medicine, 71, 568e575.

Richardson, E. A., Mitchell, R., Hartig, T., de Vries, S., Astell-Burt, T., \& Frumkin, H. (2012). Green cities and health: A question of scale? Journal of Epidemiology \& Community Health, $66,160 \mathrm{e} 165$.

Shokohi, H. (1994). New Perspectives on Urban Geography, Volume I, Sam press.

Stern, P.C., (2000). Toward a coherent theory of environmentally significant behavior. Journal of Social Issues 56, 407424.
Takano, T., Nakamura, K., \& Watanabe, M. (2002). Urban residential environments and senior citizens' longevity in megacity areas: The importance of walkable green spaces. Journal of Epidemiology \& Community Health, 56, 913e918.

Tognoli, J. (1987). Residential environments. In D. Stokols \& I. Altman, Eds., Handbook oJ

Taylor, R. B. (1984). Neighborhood physical environment and stress. In Gary W. Evans, Ed.

Teig, E., Amulya, J., Bardwell, L., Buchenau, M., Marshall, Litt, J., 2009. Collective efficacy in Denver, Colorado: strengthening neighborhoods and health through community gardens. Health \& Place 15, 1115-1122.

Teig, E., Amulya, J., Bardwell, L., Buchenau, M., Marshall, J., Litt, J., (2009). Collective efficacy in Denver, Colorado: strengthening neighborhoods and health through community gardens. Health \& Place 15, 1115-1122.

Van Poll RA. (2003) multi-attribute evaluation of perceived urban environmental quality. In: Hendrickx L, Steg WL, editors. Human decision making and environmental perception. Understanding and assessing decision making in real-life settings. Groningen, NL: Regenboog Drukkerij. p. 115-28.

Wells, N., (2000). At home with nature: effects of greenness on children's cognitive functioning. Environment \& Behavior 32, 775- 795. York: Plenum Press. 